\title{
Disease-causing point-mutations in metal-binding domains of Wilson disease protein decrease stability and increase structural dynamics
}

\author{
Ranjeet Kumar • Candan Ariöz • Yaozong Li • \\ Niklas Bosaeus $\cdot$ Sandra Rocha $\cdot$ Pernilla Wittung-Stafshede
}

Received: 5 October 2016/Accepted: 10 October 2016/Published online: 15 October 2016

(C) The Author(s) 2016. This article is published with open access at Springerlink.com

\begin{abstract}
After cellular uptake, Copper $(\mathrm{Cu})$ ions are transferred from the chaperone Atox 1 to the Wilson disease protein (ATP7B) for incorporation into $\mathrm{Cu}$ dependent enzymes in the secretory pathway. Human ATP7B is a large multi-domain membrane-spanning protein which, in contrast to homologues in other organisms, has six similar cytoplasmic metal-binding domains (MBDs). The reason for multiple MBDs is proposed to be indirect modulation of enzymatic activity and it is thus intriguing that point mutations in MBDs can promote Wilson disease. We here investigated, in vitro and in silico, the biophysical consequences of clinically-observed Wilson disease mutations, G85V in MBD1 and G591D in MBD6, incorporated in domain 4. Because G85 and G591 correspond to a conserved Gly found in all MBDs, we introduced the mutations in the well-characterized MBD4. We found the mutations to dramatically
\end{abstract}

Electronic supplementary material The online version of this article (doi:10.1007/s10534-016-9976-7) contains supplementary material, which is available to authorized users.

R. Kumar · C. Ariöz · N. Bosaeus · S. Rocha ·

P. Wittung-Stafshede $(\square)$

Department of Biology and Biological Engineering,

Chalmers University of Technology, 41296 Gothenburg,

Sweden

e-mail: Pernilla.wittung@chalmers.se

Y. Li

Department of Chemistry, Umeå University, 90187 Umeå, Sweden reduce the MBD4 thermal stability, shifting the midpoint temperature of unfolding by more than $20^{\circ} \mathrm{C}$. In contrast to wild type MBD4 and MBD4D, MBD4V adopted a misfolded structure with a large $\beta$ sheet content at high temperatures. Molecular dynamic simulations demonstrated that the mutations increased backbone fluctuations that extended throughout the domain. Our findings imply that reduced stability and enhanced dynamics of MBD1 or MBD6 is the origin of ATP7B dysfunction in Wilson disease patients with the G85V or G591D mutation.

Keywords Wilson disease $\cdot$ ATP7B $\cdot$ Metal-binding domain · Thermal stability · Circular dichroism · Molecular dynamics

\section{Introduction}

Copper $(\mathrm{Cu})$ is found in the active sites of many essential proteins that participate in key cellular reactions (Huffman and O'Halloran 2001; Puig and Thiele 2002; Harris 2003). However, free $\mathrm{Cu}$ ions are potentially toxic for cells since they are capable of producing reactive oxygen species which results in oxidative deterioration of biological molecules (Valko et al. 2005). To avoid $\mathrm{Cu}$ toxicity, the intracellular concentration of $\mathrm{Cu}$ is regulated via dedicated proteins that facilitate uptake, efflux as well as 
distribution of $\mathrm{Cu}$ to $\mathrm{Cu}$-dependent proteins and enzymes (Festa and Thiele 2011; O'Halloran and Culotta 2000; Robinson and Winge 2010). In the human cytoplasm, after the uptake of $\mathrm{Cu}$ ions (Ohrvik and Thiele 2014), the $\mathrm{Cu}$ chaperone Atox 1 transports the metal to the membrane-bound ATP7A and ATP7B (Menke's and Wilson disease proteins, respectively), two homologous $\mathrm{P}_{1 \mathrm{~B}}$-type ATPases located in the trans-Golgi network. Once transferred to ATP7A/B, the $\mathrm{Cu}$ ion is channeled to the lumen of the Golgi where it is loaded onto specific $\mathrm{Cu}$-dependent proteins and enzymes.

ATP7A/B are multi-domain membrane proteins with six cytoplasmic metal-binding domains (MBDs) connected by peptide linkers of various lengths constituting the N-terminal tail (Lutsenko et al. 2007). Each MBD in ATP7A/B, as well as Atox1, has a ferredoxin-like $\alpha / \beta$ fold and a surface-exposed invariant $\mathrm{CXXC}$ motif $(\mathrm{X}=$ any residue) in which a single $\mathrm{Cu}$ can bind to the cysteine sulfurs. In contrast to humans, bacterial and yeast $\mathrm{P}_{1 \mathrm{~B}}$-type ATPases have only one or two MBDs. The reason for the presence of multiple MBDs in ATP7A/B has been proposed to be connected with the regulation of $\mathrm{Cu}$ transfer to the Golgi lumen and $\mathrm{Cu}$-mediated protein trafficking between the Golgi and the plasma membrane (Forbes et al. 1999; LeShane et al. 2010; Hasan et al. 2012; Huang et al. 2014). During the catalytic cycle which requires ATP hydrolysis and transient phosphorylation, ATP7A/B are likely to undergo significant conformational changes and changes in domaindomain interactions (Lutsenko et al. 2007). Since there is no high-resolution structural information on the arrangement of the six MBDs within full length $\mathrm{ATP} 7 \mathrm{~A} / \mathrm{B}$, it is unclear how these domains are arranged relative to each other at different stages of the catalytic cycle. Because Atox 1 can deliver $\mathrm{Cu}$ to the MBDs (Pufahl et al. 1997; Wernimont et al. 2000; Achila et al. 2006; Banci 2006, 2008, 2009a, 2009b), one may speculate that $\mathrm{Cu}$-triggered conformational changes among these domains might initiate the catalytic cycle upon Atox1-mediated $\mathrm{Cu}$ delivery (Mondol et al. 2016). Nonetheless, it remains unclear if the direct path for $\mathrm{Cu}$ goes through the MBDs or, if Atox 1, like its bacterial homolog (Gonzalez-Guerrero and Arguello 2008), delivers $\mathrm{Cu}$ directly to a binding site at the membrane-spanning parts of ATP7A/B. It has been shown in vitro that several MBDs can be deleted/mutated without loss of $\mathrm{Cu}$ transport activity, but the presence of at least one MBD appears to be required (Forbes et al. 1999; Morin et al. 2009).

Mutations in ATP7B constitute the basis of Wilson disease, a genetic disorder where $\mathrm{Cu}$ accumulates in tissues, often resulting in neurological or psychiatric symptoms together with liver dysfunction (Thomas et al. 1995; Gitlin 2003). Over 300 missense mutations in ATP7B have been described in different patients (Huster et al. 2012), with the most common mutation being H1069Q (Caca et al. 2001; Rodriguez-Granillo et al. 2008). Taken into account the proposed indirect role of the MBDs for ATP7B function, it is noteworthy that at least 3 disease-causing missense mutations have been located in the MBDs: G85V in MBD1; L492S in MBD5; and G591D in MBD6 (Hamza et al. 1999; Hsi et al. 2008) with all three residues being strictly conserved. Using a functional assay in yeast, the introduction of G85V or L492S mutations was found to result in an inactive ATP7B (Huster 2012). Therefore, it has been suggested that these MBD mutations will cause domain instability (Hamza et al. 1999), but this has not been tested experimentally. L492 is situated in the core of the fifth metal binding domain and mutation at this position can clearly have dramatic structural effects. In contrast, G85 and G591 correspond to a conserved Gly found in all six MBDs (Hamza et al. 1999) situated in a surface-exposed turn opposite to the $\mathrm{Cu}$ binding site (Fig. 1). The predicted effects of mutations at this position are still unclear as one may argue that a loop residue would not be particularly important for the overall domain stability.

To investigate the biophysical impact of mutations of the conserved Gly in the MBDs, we here mutated the corresponding Gly (G386) in MBD4 (which we have characterized extensively previously (Niemiec et al. 2012, 2014, 2015)) to Val (V) and Asp (D) and compared the resulting variants to the wild-type protein in vitro and in silico. We discovered that both variants have dramatically lower thermal stability in parallel with increased structural dynamics as compared to the wild-type MBD4.

\section{Materials and methods}

\section{Protein preparation}

MBD4 wild-type construct in a pET21b vector (Niemiec et al. 2012, 2015) was transformed into 


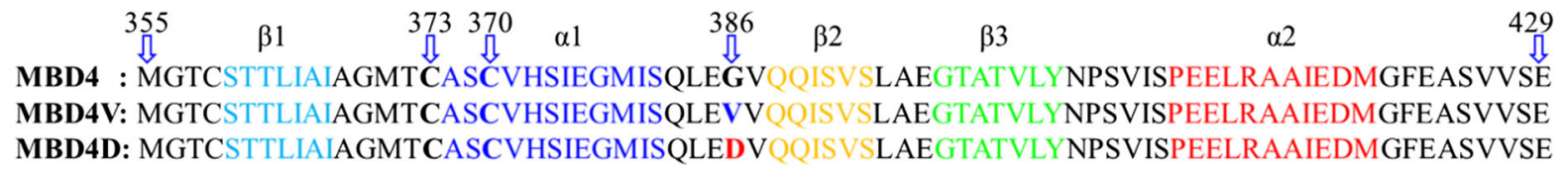

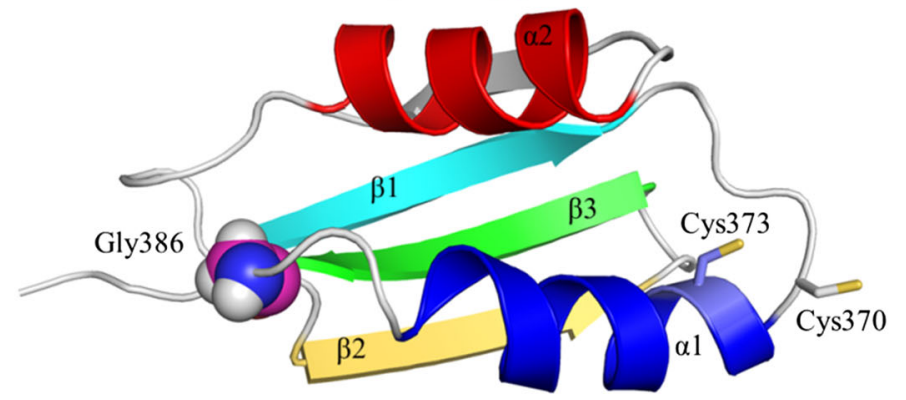

Fig. 1 Amino acid sequence and 3D structure of MBD4 variants. The color scheme of the primary sequences follows that of 3D structure; secondary structures are differently

BL21 (DE3) plysS (Novagen) cells. Transformants were first grown to an $\mathrm{OD}_{600}$ of 0.6 , and then induced with $1 \mathrm{mM}$ isopropyl $\beta$-D-1-thiogalactopyranoside (IPTG) and grown overnight at $25^{\circ} \mathrm{C}$. The cells were lysed using sonication in $20 \mathrm{mM}$ Tris- $\mathrm{HCl}$ buffer $\mathrm{pH}$ 8.0 with $2 \mathrm{mM} \mathrm{1,4-Dithiothreitol} \mathrm{(DTT)} \mathrm{and} \mathrm{in} \mathrm{the}$ presence of protease inhibitor cocktail (Roche). The centrifuged lysate was loaded onto $5 \mathrm{~mL}$ HiTrap Q HP anion exchange column (GE Healthcare) and was eluted by linear gradient with $1 \mathrm{M} \mathrm{NaCl}$ in $20 \mathrm{mM}$ Tris-HCl buffer $\mathrm{pH} 8.0$ with $2 \mathrm{mM}$ DTT. The fractions containing MBD4 were combined and concentrated with Ultra-15 Ultracel $3 \mathrm{~K}$ centrifugal filter devices. The concentrate was loaded onto Hiload 16/600 Superdex 75 column (GE Healthcare) and retrieved in $10 \mathrm{mM}$ Tris- $\mathrm{HCl}$ buffer $\mathrm{pH} 8.0$ and $1 \mathrm{mM}$ DTT. For MBD4D (MBD4 with G386D mutation, corresponding to G591D in MBD6) and MBD4V (MBD4 with G386V mutation, corresponding to G85V in MBD1), tagged versions (several tags including a repressor protein and a His-stretch with a Caspase 7 cleavage site) in pET3a constructs were transformed into BL21 (DE3) plysS (Novagen) cells, which were then grown in similar culturing conditions as used for the wild-type MBD4. The cells were harvested by centrifugation, re-suspended in Buffer A (20 mM Tris- $\mathrm{HCl} \mathrm{pH} 8,50 \mathrm{mM} \mathrm{NaCl}$ and $2 \mathrm{mM}$ DTT) and stored at $-80{ }^{\circ} \mathrm{C}$. For purification, the cell suspension was thawed and a protease inhibitor cocktail was added. After incubation on ice for $30 \mathrm{~min}$, the cells were sonicated and centrifuged. colored. Gly386 is presented as a sphere and the Cu-binding Cys are shown in stick representation

The supernatant was filtered through a $0.2 \mu \mathrm{m}$ filter and applied to $5 \mathrm{~mL}$ Hi Trap Ni-NTA column (GE healthcare). After washing the column with 5 column volume of buffer A containing $40 \mathrm{mM}$ imidazole, the protein was eluted with buffer A having $250 \mathrm{mM}$ imidazole. The tag was cleaved by adding Caspase 7 at the ratio of 1:100 (caspase 7: MBD4 mutant $w / w$ ) in the presence of $20 \mathrm{mM} \beta$-Mercaptoethanol and incubated overnight at $4{ }^{\circ} \mathrm{C}$. The cleaved protein was then loaded onto a $5 \mathrm{~mL}$ HiTrap Q HP anion exchange column (GE Healthcare) and was eluted by linear gradient with buffer A containing $1 \mathrm{M} \mathrm{NaCl}$. The eluted fractions were pooled, concentrated and loaded onto a Hiload 16/600 superdex 75 column (GE Healthcare). The obtained pure protein was finally stored at $-80{ }^{\circ} \mathrm{C}$ in $20 \mathrm{mM}$ Tris- $\mathrm{HCl}$ buffer $\mathrm{pH} 8.0$ with $50 \mathrm{mM} \mathrm{NaCl}$ and $1 \mathrm{mM}$ DTT. For all purified proteins, the sample purity was confirmed by a single band on a SDS-PAGE gel (Fig. S1) and a single elution peak in size exclusion chromatography. The concentration of the proteins was determined using $\varepsilon_{280}=1490 \mathrm{M}^{-1} \mathrm{~cm}^{-1}$ (MBD4 has one Tyr).

\section{Circular dichroism spectroscopy}

Far-UV circular dichroism (CD) spectra of MBD4 wild type and variants $(65 \mu \mathrm{M})$ in $20 \mathrm{mM}$ Tris- $\mathrm{HCl}$ buffer $\mathrm{pH} 8$ and $50 \mathrm{mM} \mathrm{NaCl}$ were recorded using a Chirascan CD spectrometer (Applied Photophysics) in $1 \mathrm{~mm}$ quartz cuvette at $6{ }^{\circ} \mathrm{C}$, with $1 \mathrm{~nm}$ steps, a bandwidth of $1 \mathrm{~nm}$ and a time-per-point of $1 \mathrm{~s}$. The 
spectra were averaged 5 times and baseline subtracted. The thermal unfolding of the proteins $(65 \mu \mathrm{M})$ was monitored at $222 \mathrm{~nm}$ in stepped ramp mode from 6 to $98{ }^{\circ} \mathrm{C}$ (with a temperature-sensitive probe inserted into the cuvette) with a bandwidth of $1 \mathrm{~nm}, 17 \mathrm{~s}$ per data point, and three repeats for each set. Experiments were performed in the absence and presence of equimolar amounts of copper to WD4. A fivefold molar excess of DTT to protein was maintained in all experiments in order to facilitate copper reduction prior to protein loading. The reversibility of protein thermal denaturation was tested by $\mathrm{CD}$-monitored cooling experiments and incubation at fixed temperatures. The $\mathrm{CD}$ data sets are reported as mean residue molar ellipticity (degrees $\mathrm{M}^{-1} \mathrm{~m}^{-1}$ ).

Molecular dynamics simulations and analysis

The systems for molecular dynamics (MD) simulations were prepared based on the solution structure 2ROP (the two-domain construct MBD3-MBD4 of human ATP7B) (Banci et al. 2008). The chain A of 2ROP, i.e., MBD4, was extracted as the target. The structure was trimmed based on the sequence in Fig. 1. The residue G386 of the wild type was exchanged in silico to V386 and D386 to generate two MBD4 variants. In total we built 3 systems, namely wild type MBD4, G386V-containing MBD4 (MBD4V) and G386D-containing MBD4 (MBD4D). The hydrogens were added to the proteins and the protonation states were tuned at neutral $\mathrm{pH}$ conditions. The prepared structure (wild type system as an example) was solvated in a $66 \AA$ rhombic dodecahedron TIP3P water box (Jorgensen et al. 1983) to ensure $10 \AA$ buffer space between the protein atoms and the boundary of the water box. $0.15 \mathrm{M}$ of $\mathrm{NaCl}$ was added to neutralize the system and mimic the physiological conditions. The system was initially minimized for 11,000 steps under a series of position restraints and constraints, then heated to $300 \mathrm{~K}$ and equilibrated under NVT condition (constant volume and temperature) for $1 \mathrm{~ns}$ using the CHARMM program (version 38a1) (Brooks 2009).

$200 \mathrm{~ns}$ production MD simulation was carried out at NPT condition (constant pressure and temperature) for each system using the NAMD program (version 2.10) (Phillips et al. 2005). The pressure was controlled by Nosé-Hoover Langevin piston method with 200 ps piston period and 100 ps piston decay time
(Feller et al. 1995). The temperature was maintained at $300 \mathrm{~K}$ by using Langevin thermostat with 5 ps friction coefficient. Integration time step was set to $2 \mathrm{fs}$, which is allowed through constraining any bond involving hydrogens by SHAKE algorithm. Non-bonded van der Waals energies were calculated using a switching function with the switching distance from 9 to $11 \AA$ (Loncharich and Brooks 1989), and electrostatic interactions were evaluated using the particle mesh Ewald summation (PME) method (Petersen 1995). The CHARMM36 force field (Best et al. 2012) with the CMAP correction (MacKerell et al. 2004) was used to present the proteins. In addition to the simulations at $300 \mathrm{~K}, \mathrm{MBD} 4$ and MBD4V were also simulated for $200 \mathrm{~ns}$ at $330 \mathrm{~K}$ using the same protocol as above. The covariance matrix analysis, principle component analysis (PCA) (Brooks et al. 1995) and geometric measurements on the simulated systems were fulfilled in CHARMM routines. All the figures of the protein structures were prepared by the PyMOL graphic software (PyMOL version 0.99, DeLano Scientific LLC, CA).

\section{Results}

Secondary structure and thermal stability in vitro

The far-UV CD spectrum at $6{ }^{\circ} \mathrm{C}$ of wild-type MBD4 displayed a broad negative band at around $222 \mathrm{~nm}$ indicating a mixture of $\beta$-sheet and $\alpha$-helix structures (Fig. 2a), as expected for a ferredoxin-like structure (Banci et al. 2008). The MBD4V and MBD4D mutants also showed characteristic CD spectra of folded structures, very similar to the spectrum of the wildtype protein. MBD4V showed a somewhat more pronounced CD band at $208 \mathrm{~nm}$ (that reports on $\alpha$ helical content) as compared to the other two variants.

Thermal unfolding experiments of the apo-forms of the variants probed by $\mathrm{CD}$ at $222 \mathrm{~nm}$ demonstrated that the wild-type protein unfolded in a partly reversible process, whereas MBD4D unfolded irreversibly (Figs. 3a, S2). The MBD4V variant had a different thermal unfolding profile in which unfolding was followed by refolding into a different structure (Figs. 3a, 4). The first change upon increasing the temperature was unfolding, as reflected in a decreased absolute CD signal at $222 \mathrm{~nm}$. Above $50{ }^{\circ} \mathrm{C}$, unfolding was followed by a significant gain of secondary 

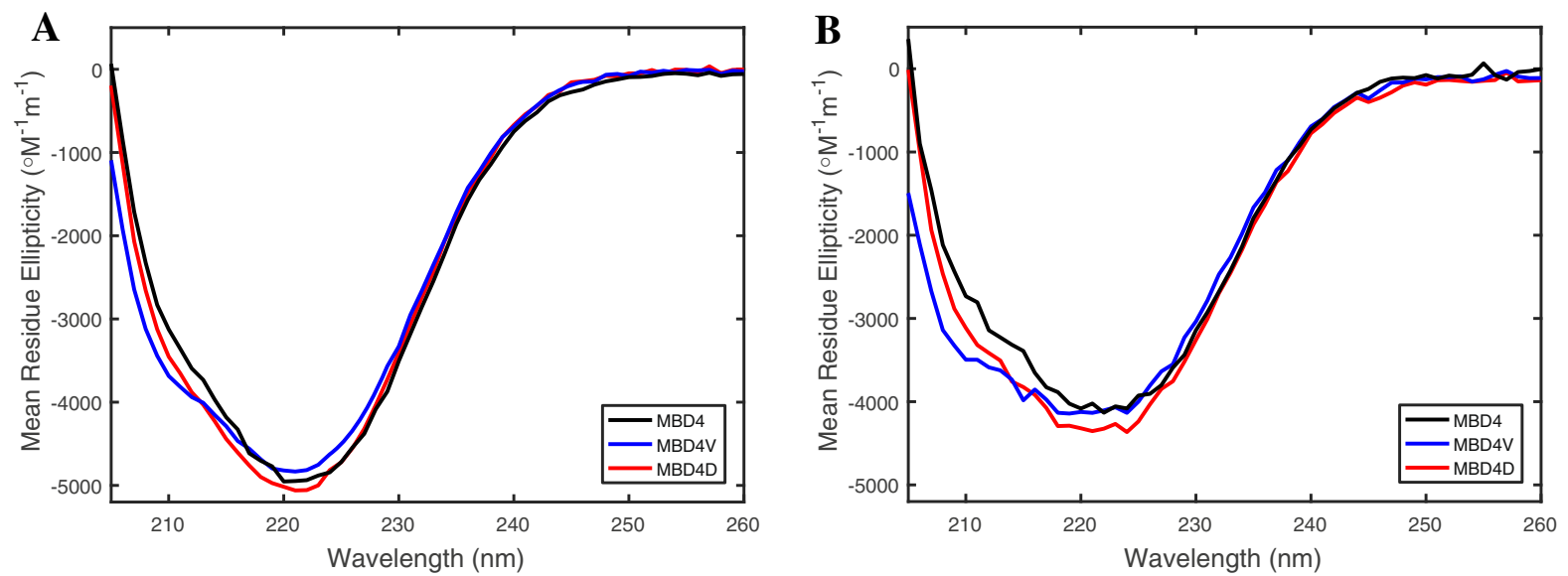

Fig. $2 \mathrm{CD}$ spectra of MBD4D (red), MBD4V (blue), and MBD4 wild-type (black): a without $\mathrm{Cu}$, and $\mathbf{b}$ in the presence of Cu in a 1:1 molar ratio of metal to protein

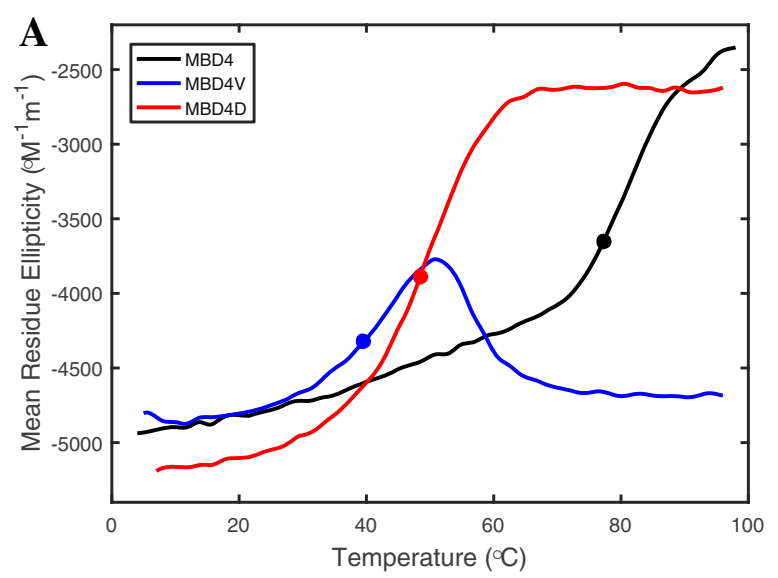

Fig. 3 Thermal unfolding profiles of MBD4D (red), MBD4V (blue), and MBD4 (black). without $\mathrm{Cu}(\mathbf{a})$ and in the presence of

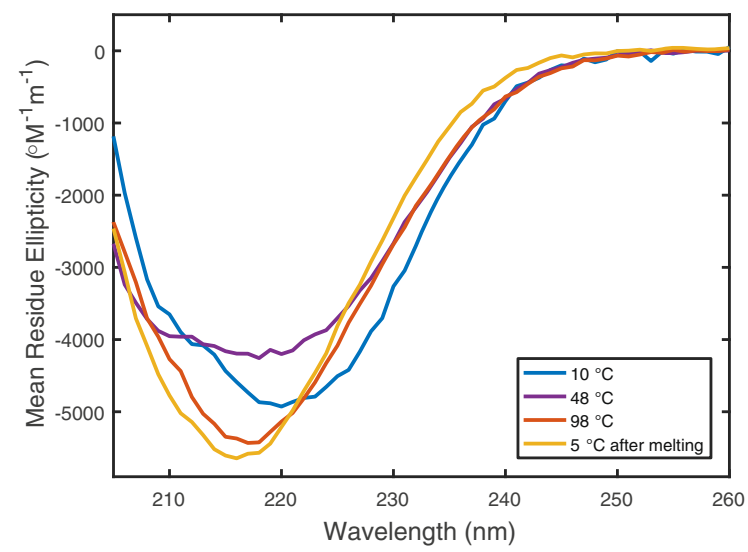

Fig. $4 \mathrm{CD}$ spectra of MBD4V at $10{ }^{\circ} \mathrm{C}$ (blue), $48{ }^{\circ} \mathrm{C}$ (purple), $98{ }^{\circ} \mathrm{C}($ red $)$, and, upon re-cooling of heated sample, at $5{ }^{\circ} \mathrm{C}$ (yellow)

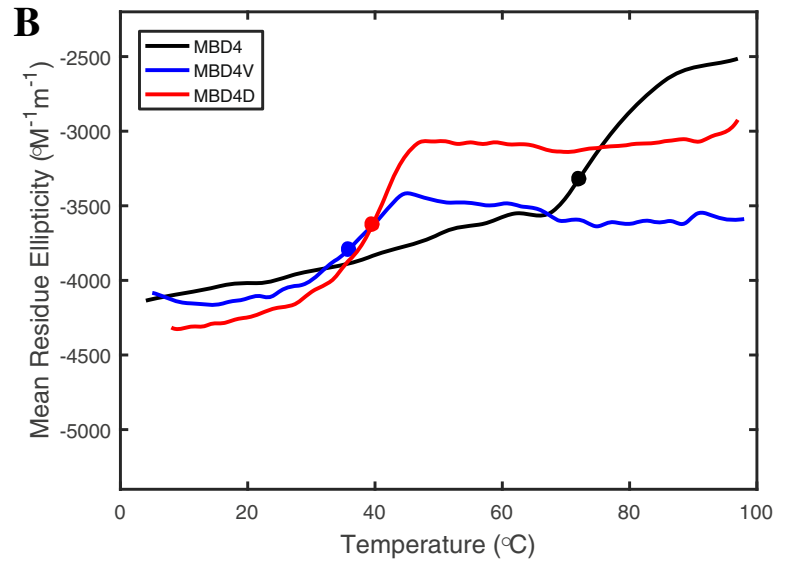

$\mathrm{Cu}$ in a 1:1 molar ratio (b) probed by $\mathrm{CD}$ at $222 \mathrm{~nm}$. Circles indicate estimated midpoints of the unfolding transitions (the first transition for MBD4V)

structure as reflected by an increased absolute CD signal at $222 \mathrm{~nm}$ (Fig. 3a). CD spectra at different temperatures during heating of MBD4V showed that at $48{ }^{\circ} \mathrm{C}$, the spectrum was characteristic of a partially-unfolded protein, whereas at higher temperatures, the spectrum was indicative of $\beta$-sheet structure (Fig. 4). We note that heating-induced protein misfolding into structures with large secondary structure content has previously been documented for other proteins (Pozdnyakova and Wittung-Stafshede 2010; Sedlak et al. 2008).

Despite the anomalous misfolding of the MBD4V variant, it is clear that both mutants had dramatically lower thermal stability (defined as the temperature at which the folded structure is lost) than the wild-type 
MBD4 (Fig. 3a). We estimated the thermal midpoints $\left(\mathrm{T}_{\mathrm{m}}\right)$ of the mutant unfolding transitions to be in the range of $40-50{ }^{\circ} \mathrm{C}$ (i.e., where $50 \%$ of the protein sample is unfolded), whereas wild-type MBD4 had a thermal midpoint above $75^{\circ} \mathrm{C}$. Thus, even though the mutations are located in a loop at the surface of the folded protein (Fig. 1), they have pronounced effects on the overall thermal stability of the MBD4 structural fold.

Both mutants, like the wild-type domain (Niemiec et al. 2012, 2015), coordinated $\mathrm{Cu}$ stoichiometrically when mixed in micromolar concentrations in the presence of 5-fold excess DTT. This is reasonable since the mutation site is opposite to the $\mathrm{Cu}$-binding site. The spectra of the holo-forms are similar to those of the apo-forms with only small changes in the CD intensity (Fig. 2b). Thermal denaturation experiments demonstrated that, when $\mathrm{Cu}$ was loaded onto the protein, the $T_{m}$ of the unfolding reactions decreased for all the variants by $5-10{ }^{\circ} \mathrm{C}$ at our conditions when compared to the apo-forms (Fig. 3b). Thermal unfolding reactions of $\mathrm{Cu}$-loaded proteins were, like for the apo-forms, partially reversible for wild-type MBD4 but irreversible for the mutants, based on $\mathrm{CD}$ data collected upon cooling (Fig. S3). The increase of the absolute CD value at $222 \mathrm{~nm}$ seen at higher temperatures for apo-MBD4V was not observed for the holoform of MBD4V. However, the spectrum of holoMBD4V after re-cooling was, as in the case of apoMBD4V, characteristic of $\beta$-sheet structure (Fig. S3).

Structural dynamics and protein motion in silico

To probe the influence of the mutations at atomistic level, we performed $200 \mathrm{~ns}$ MD simulations for each of MBD4, MBD4V and MBD4D in apo-forms. Because all-atom simulations of complete protein folding/ unfolding processes at room temperature are still computationally challenging (Scheraga et al. 2007) we here focused on variations in local structural dynamics and motions of the folded protein domain. Unless specified, analyses are based on simulations at $300 \mathrm{~K}$.

The root-mean-square-deviation (RMSD) profiles showed that MBD4V and MBD4D, especially MBD4D, experienced more pronounced structural deviations than MBD4 (Fig. 5a). The RMSD of MBD4D periodically deviated $2.5 \AA$ away from its minimized solution structure after $50 \mathrm{~ns}$, suggesting a substantial perturbation induced by the introduced Asp at position 386. The root-mean-square fluctuation
(RMSF) profiles located the perturbed regions, which corresponded to the residues around the mutated 386 position (the loop connecting $\alpha 1$ and $\beta 2$ ) and part of $\beta 2$ ranging from residue 403 to 410 (Fig. 5b). The secondary structure analysis also showed that MBD4D had lost $\beta$ structure (Fig. S4a-c) which was attributed to the distortion of $\beta 2$ (Fig. S4d). Taken together, there is augmented structural dynamics in silico upon mutation at position 386, with an Asp substitution causing more distortion than a Val substitution.

To explore how the mutations influence protein motions, we employed covariance matrix analysis and PCA. Two major differences in the correlated motions between the wild-type MBD4 and two variants were found. First, pair-wised correlations along the matrix diagonal were strengthened in MBD4V and MBD4D as compared with in MBD4. Second, the mutations produced enhanced anti-correlations throughout the whole MBD4V and MBD4D structures (Fig. 6a-c). The structural regions whose anti-correlations were mostly enhanced (boxed in Fig. 6) in MBD4V and MBD4D corresponded roughly to helices $\alpha 1$ and $\alpha 2$. The enhanced motions included shearing and breathing motions of the two helices and were structurally captured by PCA (arrows, Fig. S5). Pronounced motions may make structural units, such as $\alpha 1$ and $\alpha 2$, more prone to large-scale conformational changes.

To trace the origin of MBD4V's misfolding at high temperatures found in vitro, we also performed $\mathrm{MD}$ simulations on MBD4 and MBD4V at $330 \mathrm{~K}$. During these simulations, MBD4V underwent larger fluctuations than wild type MBD4 (Fig. S5). After $120 \mathrm{ns,}$ MBD4V experienced a significant deviation relative to its original structure (Fig. S6a), suggesting largescale conformational changes taking place. The RMSF profile showed that structural changes occurred in the end of $\alpha 1$ and in the loop between $\alpha 1$ and $\beta 1$ (Fig. S6b). Investigation of the trajectory showed that MBD4V had lost part of $\alpha 1$, resulting in an extended loop between $\alpha 1$ and $\beta 1$ (Fig. S6c, d). This elongated loop may facilitate the transition to the $\beta$-sheet-rich structure (as found experimentally).

\section{Discussion}

The mutations G85V and G591D result in Wilson disease in multiple affected family members (Loudianos et al. 1998). Because this position is highly 


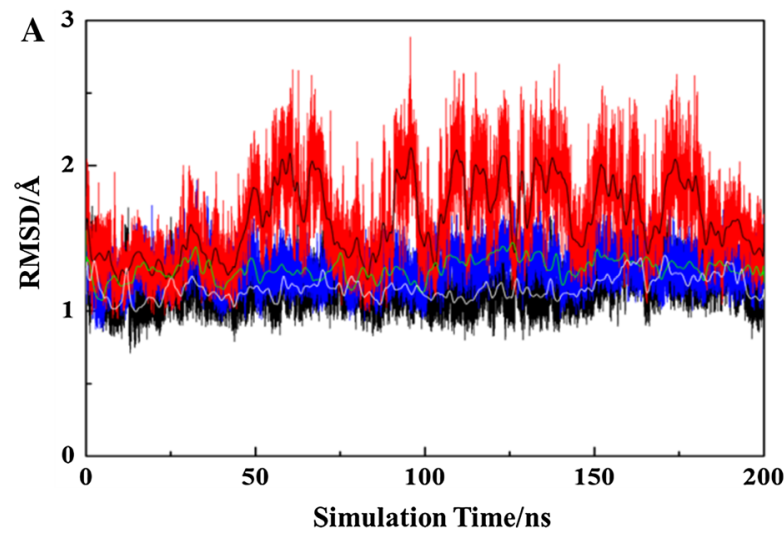

Fig. 5 Structural deviation and fluctuation of MDB4 proteins. a Backbone RMSD profiles of MBD4, MBD4V and MBD4D (black, blue and red, respectively). The smoothed curves are

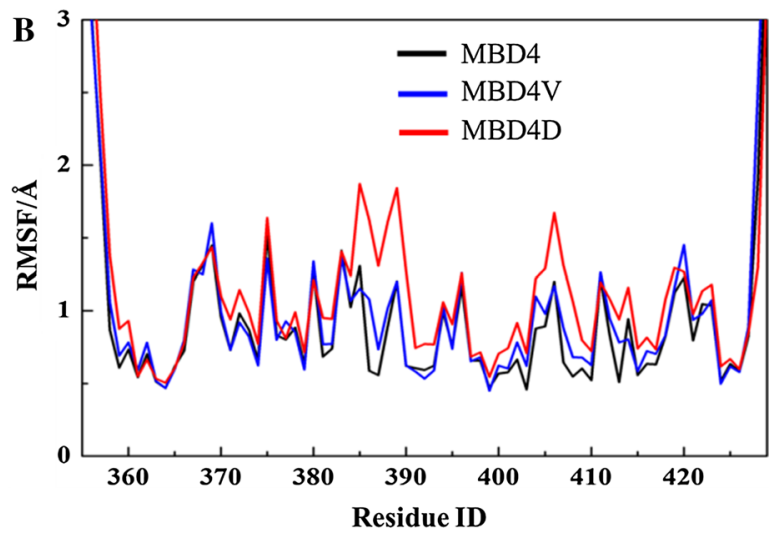

shown together with their corresponding RMSD curves. b Heavy atom RMSF profiles with the same color scheme as in (a)

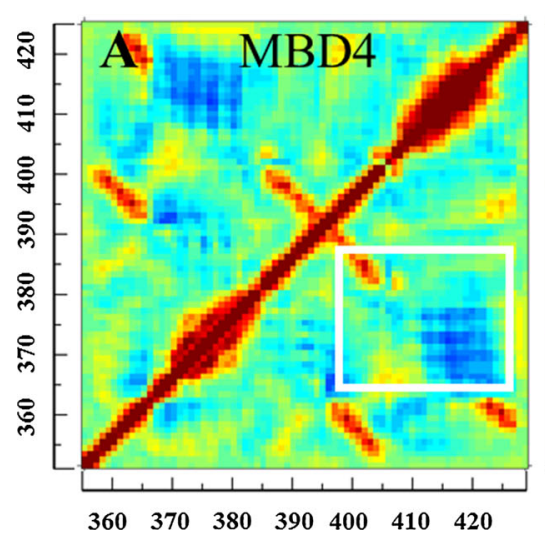

Fig. 6 Covariance matrices of MBD4 (a), MBD4V (b) and MBD4D (c) with the $\mathrm{X}$ and $\mathrm{Y}$ axes reporting on residue ID. The color scale changes from blue ( -0.6 and smaller correlation

conserved among the human MBDs, this Gly residue, despite its surface-located position, must be important for the overall ATP7B function in vivo. The question is why and how this is explained. Our experiments demonstrate that mutation of this Gly to Val or Asp in MBD4 creates pronounced domain thermal destabilization in vitro and enhanced domain structural dynamics in silico. All MBD4 variants are stable (i.e., folded and capable of binding $\mathrm{Cu}$ ) at temperatures below $10{ }^{\circ} \mathrm{C}$ but the two mutants unfold at considerably lower temperatures as compared to wild type MBD4. The lowered thermal stability of the mutants (regardless of $\mathrm{Cu}$ loading or not) and the irreversibility of the reactions suggest that, at physiological temperatures, such mutated domains will be largely unfolded. The observation that MBD4V misfolded into a new $\beta$-sheet-

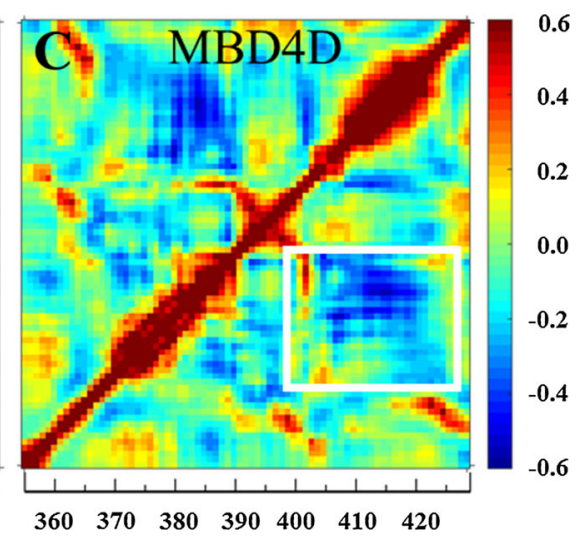

value) for anti-correlation to green (zero) for non-correlation and to red (0.6 and greater correlation value) for correlation between a pair of residues

rich species at high temperatures indicates that the MBD structural unit is prone to alternate structures and that a small increase in hydrophobicity, such as upon introducing a Val, may act as a trigger.

Although several Wilson disease mutations result in defects in ATP7B trafficking, ATP7B proteins with a G85V or G591D mutation were reported to have normal cellular localization (although this has been questioned (de Bie et al. 2007)), but they appear to be expressed at lower levels (de Bie et al. 2007; van den Berghe et al. 2009) and have impaired interactions with Atox 1 in model systems (Hamza et al. 1999). If conformational changes are strongly coupled among the six MBDs, or/ and between MBDs and other domains in ATP7B, partial/full unfolding and/or increased structural dynamics of an individual MBD may cause overall 
protein dysfunction, although occurring distant from the functional sites. Molecular studies of full-length proteins harboring these mutations are required to reveal what functional step(s) (e.g., $\mathrm{Cu}$ uptake from Atox1, ATP binding and/or hydrolysis, $\mathrm{Cu}$ movement along the MBDs or through the membrane channel, vesicle trafficking) are primarily affected by MBD1 and MBD6 instability. It is also important to assess if unfolding of one mutated domain within the full-length protein remains a local phenomenon, or if this triggers unfolding of other domains as well, resulting in widespread perturbation of the protein.

Interestingly, both G85V and G591D mutated ATP7B variants were found to have increased COMMD1 interactions (de Bie et al. 2007). It has been proposed that COMMD1 is a negative regulator of protein stability and its binding to the two ATP7B variants may thus be part of the cellular quality control system (de Bie et al. 2007). In vivo, COMMD1 interactions may block ATP7B Cu-transport activity and/or direct ATP7B for degradation. Thus one scenario is that instability/unfolding of MBD1 or MBD6 triggers COMMD1 binding that, in turn, sterically block $\mathrm{Cu}$ transport activity of the protein.

In summary, introducing a larger amino acid (Asp or Val instead of Gly) at position 386 in MBD4 (as found in MBD1 and MBD6 in Wilson disease patients) results in enhanced domain structural dynamics in silico and decreased resistance towards thermal perturbations in vitro. Our findings suggest that these two mutations cause Wilson disease in patients because of MBD structural instability that indirectly or directly affects domain-domain interactions in ATP7B which, in turn, impair the overall $\mathrm{Cu}$-transport function.

Acknowledgments Funding is acknowledged from the Knut and Alice Wallenberg foundation, the Swedish Research Council, the Chalmers Foundation and the Chemistry Department at Umeå University. Most simulations were conducted using resources provided by the Swedish National Infrastructure for Computing (SNIC) at the High Performance Computing Center North (HPC2 N) and PDC Center for High Performance Computing.

Open Access This article is distributed under the terms of the Creative Commons Attribution 4.0 International License (http:// creativecommons.org/licenses/by/4.0/), which permits unrestricted use, distribution, and reproduction in any medium, provided you give appropriate credit to the original author(s) and the source, provide a link to the Creative Commons license, and indicate if changes were made.

\section{References}

Achila D, Banci L, Bertini I, Bunce J, Ciofi-Baffoni S, Huffman DL (2006) Structure of human Wilson protein domains 5 and 6 and their interplay with domain 4 and the copper chaperone HAH1 in copper uptake. Proc Natl Acad Sci U S A 103(15):5729-5734

Banci L (2006) The Atx1-Ccc2 complex is a metal-mediated protein-protein interaction. Nature Chem Biol 2:367-368

Banci L, Bertini I, Cantini F, Rosenzweig AC, Yatsunyk LA (2008) Metal binding domains 3 and 4 of the Wilson disease protein: solution structure and interaction with the copper(I) chaperone HAH1. Biochemistry 47(28):7423-7429

Banci L, Bertini I, Calderone V, Della-Malva N, Felli IC, Neri S, Pavelkova A, Rosato A (2009a) Copper(I)-mediated protein-protein interactions result from suboptimal interaction surfaces. Biochem J 422(1):37-42

Banci L, Bertini I, Cantini F, Massagni C, Migliardi M, Rosato A (2009b) An NMR study of the interaction of the N-terminal cytoplasmic tail of the Wilson disease protein with copper(I)-HAH1. J Biol Chem 284(14):9354-9360

Best RB, Zhu X, Shim J, Lopes PE, Mittal J, Feig M, Mackerell AD Jr (2012) Optimization of the additive CHARMM all-atom protein force field targeting improved sampling of the backbone phi, psi and sidechain chi(1) and chi(2) dihedral angles. J Chem Theory Comput 8(9):3257-3273

Brooks BR, Janežič D, Karplus M (1995) Harmonic analysis of large systems. I. Methodology. J Comput Chem 16(12): 1522-1542

Brooks BR, Brooks CL 3rd, Mackerell AD Jr, Nilsson L, Petrella RJ, Roux B, Won Y, Archontis G, Bartels C, Boresch S, Caflisch A, Caves L, Cui Q, Dinner AR, Feig M, Fischer S, Gao J, Hodoscek M, Im W, Kuczera K, Lazaridis T, Ma J, Ovchinnikov V, Paci E, Pastor RW, Post CB, Pu JZ, Schaefer M, Tidor B, Venable RM, Woodcock HL, Wu X, Yang W, York DM, Karplus M (2009) CHARMM: the biomolecular simulation program. J Comput Chem 30(10):1545-1614

Caca K, Ferenci P, Kuhn HJ, Polli C, Willgerodt H, Kunath B, Hermann W, Mossner J, Berr F (2001) High prevalence of the H1069Q mutation in East German patients with Wilson disease: rapid detection of mutations by limited sequencing and phenotype-genotype analysis. J Hepatol 35(5): 575-581

de Bie P, van de Sluis B, Burstein E, van de Berghe PV, Muller P, Berger R, Gitlin JD, Wijmenga C, Klomp LW (2007) Distinct Wilson's disease mutations in ATP7B are associated with enhanced binding to COMMD1 and reduced stability of ATP7B. Gastroenterology 133(4):1316-1326

Feller SE, Zhang Y, Pastor RW, Brooks BR (1995) Constant pressure molecular dynamics simulation: the Langevin piston method. J Chem Phys 103(11):4613-4621

Festa RA, Thiele DJ (2011) Copper: an essential metal in biology. Curr Biol 21(21):R877-R883

Forbes JR, Hsi G, Cox DW (1999) Role of the copper-binding domain in the copper transport function of ATP7B, the P-type ATPase defective in Wilson disease. J Biol Chem 274(18):12408-12413 
Gitlin JD (2003) Wilson disease. Gastroenterology 125(6): 1868-1877

Gonzalez-Guerrero M, Arguello JM (2008) Mechanism of $\mathrm{Cu}+$-transporting ATPases: soluble $\mathrm{Cu}+$ chaperones directly transfer $\mathrm{Cu}+$ to transmembrane transport sites. Proc Natl Acad Sci U S A 105(16):5992-5997

Hamza I, Schaefer M, Klomp LW, Gitlin JD (1999) Interaction of the copper chaperone HAH1 with the Wilson disease protein is essential for copper homeostasis. Proc Natl Acad Sci U S A 96(23):13363-13368

Harris ED (2003) Basic and clinical aspects of copper. Crit Rev Clin Lab Sci 40(5):547-586

Hasan NM, Gupta A, Polishchuk E, Yu CH, Polishchuk R, Dmitriev OY, Lutsenko S (2012) Molecular events initiating exit of a copper-transporting ATPase ATP7B from the trans-Golgi network. J Biol Chem 287(43):36041-36050

Hsi G, Cullen LM, Macintyre G, Chen MM, Glerum DM, Cox DW (2008) Sequence variation in the ATP-binding domain of the Wilson disease transporter, ATP7B, affects copper transport in a yeast model system. Hum Mutat 29(4):491-501

Huang Y, Nokhrin S, Hassanzadeh-Ghassabeh G, Yu CH, Yang H, Barry AN, Tonelli M, Markley JL, Muyldermans S, Dmitriev OY, Lutsenko S (2014) Interactions between metal-binding domains modulate intracellular targeting of $\mathrm{Cu}(\mathrm{I})$-ATPase ATP7B, as revealed by nanobody binding. J Biol Chem 289(47):32682-32693

Huffman DL, O'Halloran TV (2001) Function, structure, and mechanism of intracellular copper trafficking proteins. Annu Rev Biochem 70:677-701

Huster D, Kuhne A, Bhattacharjee A, Raines L, Jantsch V, Noe J, Schirrmeister W, Sommerer I, Sabri O, Berr F, Mossner J, Stieger B, Caca K, Lutsenko S (2012) Diverse functional properties of Wilson disease ATP7B variants. Gastroenterology 142(4):947-956

Jorgensen WL, Chandrasekhar J, Madura JD, Impey RW, Klein ML (1983) Comparison of simple potential functions for simulating liquid water. J Chem Phys 79(2):926-935

LeShane ES, Shinde U, Walker JM, Barry AN, Blackburn NJ, Ralle M, Lutsenko S (2010) Interactions between copperbinding sites determine the redox status and conformation of the regulatory N-terminal domain of ATP7B. J Biol Chem 285(9):6327-6336

Loncharich RJ, Brooks BR (1989) The effects of truncating longrange forces on protein dynamics. Proteins 6(1):32-45

Loudianos G, Dessi V, Lovicu M, Angius A, Nurchi A, Sturniolo GC, Marcellini M, Zancan L, Bragetti P, Akar N, Yagci R, Vegnente A, Cao A, Pirastu M (1998) Further delineation of the molecular pathology of Wilson disease in the Mediterranean population. Hum Mutat 12(2):89-94

Lutsenko S, Barnes NL, Bartee MY, Dmitriev OY (2007) Function and regulation of human copper-transporting ATPases. Physiol Rev 87(3):1011-1046

MacKerell AD Jr, Feig M, Brooks CL 3rd (2004) Improved treatment of the protein backbone in empirical force fields. J Am Chem Soc 126(3):698-699

Mondol T, Aden J, Wittung-Stafshede P (2016) Copper binding triggers compaction in N-terminal tail of human copper pump ATP7B. Biochem Biophys Res Commun 470(3):663-669

Morin I, Gudin S, Mintz E, Cuillel M (2009) Dissecting the role of the N-terminal metal-binding domains in activating the yeast copper ATPase in vivo. FEBS J 276(16):4483-4495
Niemiec MS, Weise CF, Wittung-Stafshede P (2012) In vitro thermodynamic dissection of human copper transfer from chaperone to target protein. PLoS One 7(5):e36102

Niemiec MS, Dingeldein AP, Wittung-Stafshede P (2014) T versus D in the MTCXXC motif of copper transport proteins plays a role in directional metal transport. J Biol Inorg Chem 19(6):1037-1047

Niemiec MS, Dingeldein AP, Wittung-Stafshede P (2015) Enthalpy-entropy compensation at play in human copper ion transfer. Sci Rep 5:10518

O'Halloran TV, Culotta VC (2000) Metallochaperones, an intracellular shuttle service for metal ions. J Biol Chem 275(33):25057-25060

Ohrvik H, Thiele DJ (2014) How copper traverses cellular membranes through the mammalian copper transporter 1, Ctr1. Ann N Y Acad Sci 1314:32-41

Petersen HG (1995) Accuracy and efficiency of the particle mesh Ewald method. J Chem Phys 103(9):3668-3679

Phillips JC, Braun R, Wang W, Gumbart J, Tajkhorshid E, Villa E, Chipot C, Skeel RD, Kale L, Schulten K (2005) Scalable molecular dynamics with NAMD. J Comput Chem 26(16):1781-1802

Pozdnyakova I, Wittung-Stafshede P (2010) Non-linear effects of macromolecular crowding on enzymatic activity of multi-copper oxidase. Biochim Biophys Acta 1804(4):740-744

Pufahl RA, Singer CP, Peariso KL, Lin SJ, Schmidt PJ, Fahrni CJ, Culotta VC, Penner-Hahn JE, O'Halloran TV (1997) Metal ion chaperone function of the soluble $\mathrm{Cu}(\mathrm{I})$ receptor Atx1. Science 278(5339):853-856

Puig S, Thiele DJ (2002) Molecular mechanisms of copper uptake and distribution. Curr Opin Chem Biol $6(2): 171-180$

Robinson NJ, Winge DR (2010) Copper metallochaperones. Annu Rev Biochem 79:537-562

Rodriguez-Granillo A, Sedlak E, Wittung-Stafshede P (2008) Stability and ATP binding of the nucleotide-binding domain of the Wilson disease protein: effect of the common H1069Q mutation. J Mol Biol 383(5):1097-1111

Scheraga HA, Khalili M, Liwo A (2007) Protein-folding dynamics: overview of molecular simulation techniques. Annu Rev Phys Chem 58:57-83

Sedlak E, Zoldak G, Wittung-Stafshede P (2008) Role of copper in thermal stability of human ceruloplasmin. Biophys $\mathrm{J}$ 94(4):1384-1391

Thomas GR, Forbes JR, Roberts EA, Walshe JM, Cox DW (1995) The Wilson disease gene: spectrum of mutations and their consequences. Nat Genet 9(2):210-217

Valko M, Morris H, Cronin MT (2005) Metals, toxicity and oxidative stress. Curr Med Chem 12(10):1161-1208

van den Berghe PV, Stapelbroek JM, Krieger E, de Bie P, van de Graaf SF, de Groot RE, van Beurden E, Spijker E, Houwen RH, Berger R, Klomp LW (2009) Reduced expression of ATP7B affected by Wilson disease-causing mutations is rescued by pharmacological folding chaperones 4-phenylbutyrate and curcumin. Hepatology 50(6):1783-1795

Wernimont AK, Huffman DL, Lamb AL, O'Halloran TV, Rosenzweig AC (2000) Structural basis for copper transfer by the metallochaperone for the Menkes/Wilson disease proteins. Nat Struct Biol 7(9):766-771 